\title{
A LUTA DO CAMPONÊS POR UMA EDUCAÇÃO ESPECÍFICA PARA O MEIO RURAL NO AMBIENTE EM QUE SE ENCONTRA.
}

\section{Andréa Carolina Lopes de Aguilar \\ Luiz Bezerra Neto}

\begin{abstract}
Resumo
Este artigo busca discutir a educação no MST e como esta se constitui em parte fundamental da luta do movimento e também no processo de luta pela terra, deixando claro que não é uma educação desvinculada a tudo o que os sujeitos sem terra lutam e sim uma educação específica, com parâmetros específicos, currículos específicos, ou seja, uma pedagogia voltada para o cotidiano dos educandos do meio rural.
\end{abstract}

Palavras- chave: educação do campo, educação Rural, Movimento Sem Terra.

\begin{abstract}
This article tries to discuss the education inside the MST and how this is an important part in their struggle and also in the process of the struggling for land, making clear that it's not an education concept unlinked with their mains struggles, but an specific education, with specific parameters and aims, an education thought for the daily lives of learners that live in rural areas.
\end{abstract}

Keywords: educação do campo, educação Rural, Movimento Sem Terra.

\section{A LUTA DO CAMPONÊS POR UMA EDUCAÇÃO ESPECÍFICA PARA O MEIO RURAL NO AMBIENTE EM QUE SE ENCONTRA.}

Neste artigo abordaremos a educação no Movimento dos Trabalhadores Rurais Sem Terra - MST, discutindo como esta se constitui em parte fundamental na luta do movimento e também no processo de luta pela terra, deixando claro não ser esta uma educação desvinculada dos seus valores, sua identidade e suas ideologias, mas uma educação que busca ser específica, com parâmetros específicos, currículos específicos, ou seja, uma pedagogia voltada para o cotidiano dos educandos do meio rural. 
Para entender este processo, devemos ressaltar que o MST é um dos mais importantes movimentos sociais do país e que tem um papel fundamental na luta por uma educação igualitária para o povo do campo, assim visando o meio em que vivem e suas especificidades para que o sujeito do campo não perca sua identidade de sujeito Sem Terra. Como cita Caldart (2004).

(...) é a própria realidade como se apresenta o MST hoje que coloca a análise da dimensão cultural como uma das possibilidades de sua compreensão histórica. Trata-se de um movimento social que se foi constituindo historicamente também pela força de seus gestos, pela postura de seus militantes e pela riqueza de seus símbolos. Do chapéu de palha das primeiras ocupações de terra ao boné vermelho das marchas pelo Brasil, os Sem Terra se fazem identificar por determinadas formas de luta, pelo estilo de suas manifestações públicas, pela organização que demonstram, pelo seu jeito, enfim, por sua identidade (CALDART, 2004, p. 43-44).

Nesse sentido é que devemos pensar na educação dos sujeitos Sem Terra como uma forma de reforçar sua identidade, ou seja, esta deve ser definida coletivamente pelos próprios sujeitos do campo.

Para os educadores ligados ao MST, a educação que se dá no campo deve fazer sentido na vida do educando e no seu cotidiano. O professor e o educando, devem compreender o ambiente no qual estes vivem, suas vidas, seu trabalho, sua cultura e as relações sociais engendradas nesse meio.

Partindo deste princípio é que os educadores ligados ao MST encaram a educação para o sujeito do campo como uma possibilidade que eles têm de expressar seus interesses e necessidades e não somente reproduzir os valores do meio urbano. Por esta razão a luta por uma educação específica, com currículos específicos, e uma pedagogia específica para o meio são consideradas essenciais para que o sujeito do campo possa vir a fortalecer ainda mais sua identidade de sujeito rural, problematizando seus valores, sua cultura, seu cotidiano e, suas vivências dentro da sociedade e, assim poder pensar para além da escola rural tradicional, que não tem buscado a inserção desse sujeito do campo como produtor do conhecimento.

Nesse sentido, reivindica-se o acesso a todos os conhecimentos produzidos pela humanidade, como forma de desenvolver esta pedagogia a luz das palavras de Paulo Freire, quando este afirma: "Percebo que a luta engendra um sabor em certo nível. Sempre que se luta e peleja há uma certa noção, há uma certa claridade sobre aquilo que se luta, há uma noção de remover obstáculos." (FREIRE, 2001, p. 22”), ou seja, 
cabe aos homens transformar a realidade em que vivem e, para tal se faz necessário a práxis, a reflexão e ação dos homens sobre o mundo para assim poder transformá-lo, por isso a necessidade de uma educação que conscientize o sujeito do campo reforçando, com isso, suas raízes, na busca de uma educação includente e democrática, que os façam refletir, fazendo com que a ação educativa também seja uma ação transformadora e libertadora.

Quando colocamos esses conceitos no panorama da educação popular notamos ainda pelas palavras de Paulo Freire (2001), como este analisa, que o educando se redescobre e descobre o mundo ao mesmo tempo, tomando consciência desse mundo e levando muito mais do que o acúmulo de conhecimentos, pois leva, sobretudo, a reflexão sobre a palavra do educador. Para Freire, é necessário lembrar que tudo isso está intrínseco na vivência do educando, na sua experiência, unida ao fazer no seu cotidiano, no seu assentamento ou acampamento, é para isso que a escola no campo e a educação no e do campo tem que servir, e não apenas como um lugar no qual depositam os sujeitos do campo e que não se faz e nada mais além disso, sem um currículo, um planejamento e um material pedagógico que leve em conta as vivências do sujeito rural.

Pensando nessas possibilidades, o MST tem defendido que há a necessidade de políticas públicas que incentivem a construção de escolas nos assentamentos e acampamentos, pois, segundo o movimento, o fato do sujeito do campo ter que se deslocar para o meio urbano acaba por disseminar a idéia de que o espaço urbano é superior ao meio rural, e que a vida na cidade oferece acesso a bens e serviços que não há no campo, idealizando a cidade como um lugar de desenvolvimento enquanto que o meio rural seria o lugar do atraso, da ignorância, da pobreza, ou seja, os sujeitos rurais nas escolas do meio urbano acabariam por desvalorizar a vida do campo, diminuindo a autoestima dos alunos e descaracterizando suas identidades, daí a necessidade da educação também se constituir enquanto um instrumento de reprodução e expansão da estrutura agrária.

Nesse caso fica evidenciado que educação no campo passa a constituir-se em uma via emancipatória, que deve incentivar os sujeitos que habitam no campo a pensar e agir por si próprios, assumindo sua condição de sujeitos da aprendizagem, do trabalho e da cultura.

Nesta perspectiva emancipar adquire o sentido de obter a possibilidade de o sujeito que habita o campo tomar suas próprias decisões, segundo seus interesses e necessidades. Sendo assim, as populações do campo passariam a ter o direito de definir 
seus próprios caminhos, seus interesses, aquilo que acham pertinente aprender em consonância com sua cultura, suas lutas e seu cotidiano.

Como forma de possibilitar a formação de educadores para o campo,os movimentos sociais, em consonância com o governo federal, tem tomado algumas ações em relação à educação do campo. Como exemplo destas ações, destacamos a criação do PRONERA (Programa Nacional de Educação na Reforma Agrária). Esse programa surgiu a partir das reivindicações dos trabalhadores rurais pelo o direito a educação. $\mathrm{O}$ PRONERA foi criado após "O I Censo da Reforma Agrária no Brasil”, realizado em 1998, e visa atender principalmente os assentados que vivem em áreas de reforma agrária no país. ${ }^{1}$

Esses são alguns dos indicadores que demonstram a necessidade de se estabelecer algumas políticas públicas para a população que vive no meio rural brasileiro, sobretudo, visando ampliar o direito de acesso e de permanência na escola, pois se não fossem as lutas dos movimentos talvez nem hovesse sido criado o PRONERA, programa destinado aos camponeses.

Alguns autores consideram que os assentados rurais, por intermédio dos programas de reforma agrária fazem parte de um grupo de camponeses, constituindo assim, o que chamam de campesinato. A expressão campesinato designa um estrato da população brasileira que conseguiu terras por assentamentos ou créditos fundiários. $\mathrm{O}$ outro estrato seria a burguesia agrária que acabou por lucrar com esse modelo capitalista de agricultura (FERNANDES, 2004, p. 5).

Os camponeses têm uma terra pequena e seus gastos acabam sendo enormes por estarem inseridos numa agricultura capitalista que se utiliza de tecnologias modernas, com o uso de sementes híbridas e ou transgênicas e os demais insumos industriais adquiridos de empresas transnacionais (CARVALHO, 2003, p. 18), implementos que dificilmente são acessíveis aos camponeses.

Assim, de acordo com este autor, os pequenos proprietários afundaram-se em dívidas caindo na pobreza, passando a depender do governo. Nesse sentido, Horácio Martins de Carvalho afirma que:

É responsabilidade dos movimentos e organizações sociais e sindicais no campo aprofundar a explicação da realidade brasileira no sentido de melhor caracterizar esses dois estratos da agricultura familiar, a pequena burguesia agrária e o campesinato, de maneira a diferenciar as suas reivindicações com relação às políticas públicas

\footnotetext{
${ }^{1}$ www.unochapeco.edu.br/?cod_orgao; acessado em 26/06/2009.
} 
(CARVALHO, 2003, p. 19).

Para este autor, os trabalhadores rurais precisam conscientizar-se dos efeitos nocivos dessa política capitalista, libertando-se desse sistema, no qual eles cada vez mais empobrecem. Cabe, então, a educação ser um dos instrumentos para a libertação desses trabalhadores, pois, o autor acredita que se os trabalhadores rurais como sujeitos do processo dialógico pensarem a respeito de ser e como ser no meio em que vivem, assim conscientes de estarem se envolvendo em movimentos sociais, poderão romper as cercas da expropriação a que são submetidos.

Por isso o MST (Movimento dos Trabalhadores Rurais Sem Terra) defende a necessidade de uma educação no e do campo que além de alfabetizar leve em consideração o meio em que vivem. Ocorre que o desenvolvimento capitalista concentra as terras ao mesmo tempo em que empurra a população rural cada vez mais para os centros urbanos, causando o desemprego e consequentemente aumentando a miséria.

Nesse sentido o objetivo dos movimentos que atuam no campo é construir uma educação do campo e não do meio rural, pois segundo Bernardo Mançano Fernandes e Roseli Salete Caldart (2004, p. 22) a expressão campo tem por objetivo incluir no processo uma reflexão sobre o sentido atual do trabalho camponês e das lutas sociais e culturais que atualmente tentam garantir a sobrevivência destes trabalhadores.

Para estes autores,

(...) quando discutimos a educação do campo estamos tratando da educação que se volta ao conjunto dos trabalhadores e das trabalhadoras do campo, sejam os camponeses, incluindo os quilombolas, sejam as nações indígenas, sejam os diversos tipos de assalariados vinculados à vida $\mathrm{e}$ ao trabalho no meio rural (FERNANDES, CERIOLI \& CALDART, 2004, p. 22) ${ }^{2} \%$.

Para entender a luta do MST por uma educação do campo, é preciso que se diga que foi a partir das lutas dos excluídos do campo que o Movimento dos Trabalhadores Rurais Sem Terra foi formando-se e tornando-se um dos movimentos sociais mais importantes do Brasil.

O MST nasceu das lutas concretas pela conquista da terra, que os trabalhadores rurais foram desenvolvendo de forma isolada na região Sul, num momento em que aumentava a concentração de terras e ampliava a expulsão dos pobres da área rural, devido à modernização da agricultura e à crise do processo de colonização implementado pelo regime militar (BEZERRA NETO, 1998, p. 18).

\footnotetext{
${ }^{2}$ A I Conferência Nacional "Por uma Educação Básica do Campo" aconteceu em Luziânia, Goiás, de 27 a 31 de julho de 1998, e teve como principal objetivo "ajudar a recolocar o rural e a educação que a ele se vincula, na agenda política do país" (Fernandes, Cerioli \& Caldart, 2004, p. 22.).
} 
O movimento dos trabalhadores rurais sem terra, desde seu surgimento tem lutado por uma educação do campo e pela reforma agrária, exigindo que a estrutura para tal deva ser garantida pelo Estado. A reforma agrária exigida pelo movimento seria a redistribuição de terras, modificando as relações de trabalho, propriedade privada e modos de produção que estão nas mãos das elites agrárias. Esse discurso é contraditório, à medida que:

Ao mesmo tempo em que o MST afirma lutar por uma sociedade socialista, em que devem ser rompidas as barreiras do direito "sagrado" da propriedade através das ocupações de terras no campo, aceita e defende a pequena propriedade rural, contribuindo para ampliar e fortalecer as relações capitalistas de produção no campo, apesar de este setor ter sido historicamente considerado um entrave nas lutas para a construção de uma sociedade socialista, dado seu caráter conservador (BEZERRA NETO, 1998, p. 19).

Salientando, que de acordo com o seu discurso, o MST busca a emancipação de todos os trabalhadores, começando pelo trabalhador do campo que nesse caso, é chamado a exercer uma função demiúrgica de emancipar a classe trabalhadora de toda a exploração a ela imposta.

É importante ressaltar que o campo tem sido um importante gerador de riquezas para o nosso país, por isso não pode ser desvalorizado. Isto posto, ficam as considerações em torno da percepção de quase ausência de políticas públicas que garantam direitos ao homem do campo, principalmente em relação à educação, o que, poderia contribuir para tornar o trabalho agrícola melhor qualificado e mais inserido na produção de mercadorias que tanto se defende.

A dificuldade do acesso a educação no campo resulta de um processo econômico, social, cultural e de políticas educacionais em nosso país, que deixou como herança a precariedade no funcionamento das escolas rurais, a infraestrutura, a má formação dos professores e professores formados no meio urbano que não conhece as especificidades do meio rural, os espaços físicos inadequados, entre outros fatores.

Nessa perspectiva podemos constatar que na escola do campo predomina apenas uma concepção, ou seja, aquela que, através da relação cidade-campo dissemina os valores_e os conhecimentos contidos no cotidiano urbano, bem como atitudes distintas do modo de vida e da cultura daquela população em relação ao meio rural.

Ressaltando que a LDB 9394, (Lei de Diretrizes e Bases Nacional, de 1996), estabelece no ART. 28, que, na oferta de educação básica para a população rural, os 
sistemas de ensino deverão promover as adaptações necessárias a sua adequação às peculiaridades da vida rural de cada região, especialmente no que diz respeito aos:

I) Conteúdos curriculares e metodologias apropriadas as reais necessidades e interesses do aluno da zona rural.

II) Organização escolar própria, incluindo adequação do calendário escolar às fases do ciclo agrícola e às condições climáticas.

III) Adequação a natureza do trabalho na zona rural.

Ocorre que o que a LDB especifica é apenas a oferta da educação básica para a população rural, assegurando que os sistemas promovam as adaptações necessárias à sua adequação às peculiaridades da vida rural e de cada região. Apesar disso, podemos verificar que os governos fizeram pouco progresso no sentido de estabelecer políticas e práticas efetivas para a educação no meio rural brasileiro.

$\mathrm{Na}$ origem dessas iniciativas governamentais em nossa sociedade, é possível identificar diversas articulações e mobilizações da população rural que, através de suas organizações e movimentos sociais, reivindicam novas políticas públicas que garantam não apenas o acesso à educação, mas, fundamentalmente, a construção de uma escola e de uma educação do campo.

No entanto, muito mais que uma simples mudança de rural para campo trata-se de a expressão educação do campo ser um dos traços marcantes da identidade de sujeitos Sem Terra para o movimento, na luta por políticas públicas que garantam o direito da população rural a uma educação que seja no e do campo.

É um movimento que, conforme destaca Caldart (2004), mais que o direito da população ser educada no lugar no qual vive, torna-se o direito a uma educação pensada desde o seu lugar e com sua participação, vinculada à sua cultura e às suas necessidades humanas e sociais.

Partindo do pressuposto da educação ter como base a formação do cidadão politicamente, socialmente e culturalmente, fazendo com que ele consiga se identificar historicamente no meio em que vive e perceber as distintas identidades existentes na sociedade.

Assim a educação do campo deve pensar desde os interesses sociais, políticos e culturais dos trabalhadores rurais a que ela se destina, devido ao fato de ser um vínculo 
com sujeitos sociais concretos, mas com um recorte específico sem deixar a universalidade (CALDART, 2001, p.5).

Ao analisarmos como está a educação no campo observamos em primeiro lugar a dificuldade de acesso e nos lugares que oferecem esse ensino há sempre uma ampla discussão sobre a sua qualidade.

Na I Conferência Nacional por uma Educação Básica no Campo (1998), foi discutido a respeito da precariedade da educação no campo deixando claro sua importância. Como afirma Roseli Salete Caldart "o campo é espaço de vida digna e é legítima a luta para as políticas públicas específicas e por um projeto educativo próprio para seus sujeitos..” (2004, p. 1). Foram aprovadas nessa conferência as diretrizes operacionais para a educação básica nas escolas do campo.

A luta pela educação no campo deve ser pensada primeiramente através da luta pela formação de todos os sujeitos desse meio. Uma formação que parta de sua realidade específica, mas, que possa ser o mais amplo possível, de forma a dar a esses sujeitos a oportunidade de ter acesso a todo conhecimento produzido pela humanidade, ou seja, ter acesso ao conhecimento que a burguesia se apropria e nega à classe trabalhadora e, portanto com metodologias específicas para uma melhor qualidade de vida dos trabalhadores e moradores do campo. Sendo assim, considera-se que o sujeito do campo tem que se libertar dos estereótipos que estão arraigados por outras culturas e valorizar-se, podendo assim fazer parte de um processo emancipatório, ou seja, o campo necessita como já citamos de políticas públicas de incentivo e de propostas educacionais relacionadas aos interesses dos sujeitos do campo. De acordo com Nascimento:

Os princípios deste projeto de política educacional da Educação Básica do Campo. São eles: o princípio pedagógico do papel da escola enquanto_formadora de sujeitos articulada a um projeto de emancipação humana; princípio pedagógico da valorização de diferentes saberes no processo educativo; o princípio pedagógico dos espaços e dos tempos de formação dos sujeitos da aprendizagem; o princípio pedagógico do lugar da escola vinculado à realidade sujeitos; o princípio pedagógico da educação como estratégia para o desenvolvimento sustentável e o princípio pedagógico da autonomia e colaboração entre os sujeitos do campo e o sistema nacional de ensino. É uma revelação do quanto se avançou na perspectiva do construto de uma política pública setorial (NASCIMENTO, 2004 p. 10).

Essa luta, de acordo com o MST, deve buscar a superação da exploração enfrentada por toda a população do campo. Por isso é necessário reforçar a importância 
de uma práxis que se daria através da reflexão e ação dos homens sobre o mundo para assim transformá-lo.

Os educadores do campo, nesse sentido, devem buscar a vontade de mudança dos educandos e de si mesmos. Eles devem ensinar no campo para que seus alunos cresçam e se superem, não para abandonar o meio rural e suas causas, mas crescer dentro desse meio e lutar por essa causa.

Por isso deve existir no educador uma convicção de que mudar é possível.

No mundo da História, da cultura, da política, constato não para me adaptar mas mudar (...) Ninguém pode estar no mundo, com o mundo e com os outros de forma neutra. Não posso estar no mundo de luvas nas mãos constatando apenas (FREIRE, 1996, p. 77).

Observamos, então, a importância de uma pedagogia, enquanto didática e não enquanto conteúdo, que seja diferenciada no campo, e como esta traria a reflexão sobre como esse processo deve acontecer bem como a necessidade de múltiplos apoios, seja do governo, igreja, Ong's ou mesmo da sociedade civil.

Como agente dessa pedagogia diferenciada, a educação do campo necessita de educadores que saibam como ensinar no meio rural, para tal deve haver uma formação específica de educadores para atuarem nesse meio, ou que conheçam essa realidade para partir dela. Como diz Roseli Caldart,

Não se trata de 'inventar' um ideário para Educação do Campo; isso não repercutiria na realidade concreta [...] e nem seria uma verdadeira teoria. O desafio que temos, enquanto sujeitos que colocaram esta 'bandeira em marcha', é de abstrair das experiências, dos debates, das disputas em curso, um conjunto de idéias que possam orientar o pensar (especialmente dos educadores) sobre a prática de educação da classe trabalhadora do campo; e, sobretudo, possam orientar e projetar outras práticas e políticas de educação (CALDART, 2004, p. 3).

Nessa perspectiva, um fator que requer atenção é o formato da escola que se pensa para o meio rural, é necessário que seja uma escola capaz de atender as tarefas formais da escolarização, mas sem deixar de lado a formação que o educando deve ter , nesse sentido o educador deve refletir sobre o desenvolvimento do seu trabalho para alcançar esses objetivos, ou seja, que se alcance os objetivos reais e não apenas os proclamados, que segundo Caldart (2004, p. 3), seria avançar na clareza teórica e de projeto para poder dar um grande salto de qualidade das lutas políticas e nas práticas pedagógicas, dando conteúdo à bandeira criada por esta luta e pensando sempre o que é a educação do campo: 
Este desafio se desdobra em três tarefas combinadas: manter viva a memória da Educação do Campo, continuando e dinamizando sua construção e reconstrução pelos seus próprios sujeitos; identificar as dimensões fundamentais da luta política a ser feita no momento atual; seguir na construção do projeto político e pedagógico da Educação do Campo (CALDART, 2004, p. 3).

Essa problemática deve ser bastante discutida, gerando uma reflexão sobre as escolas no campo, para crianças, jovens e adultos, com currículos específicos, que também haja escolas em todos os assentamentos e acampamentos com os mesmos subsídios que são oferecidos para as escolas dos centros urbanos. O que podemos perceber é o fato de a luta pela educação no campo já está sendo debatida em agendas dos governos e congressos de movimentos sociais e sindicais.

A luta pela educação no campo, já mostra avanços, mas ainda falta muito para que os moradores e trabalhadores do campo possam realmente ter um ensino de qualidade que atenda as suas necessidades de ensino-aprendizagem que os oriente para o trabalho. Como segundo Caldart:

É por isso também, que são bem mais comuns as pedagogias que se colocam para os oprimidos, os trabalhadores e os movimentos sociais, e não as pedagogias que são deles próprios. Quando a luta social passa a ser vista como educativa, necessariamente se altera o olhar sobre quem são os sujeitos educadores. Também na pedagogia é possível tentar virar o mundo de ponta-cabeça, ou pelo menos passa a olhar-lo desde um outro ponto de vista (CALDART, 2004. p. 340).

A partir do momento que os trabalhadores se conscientizarem e se sentirem parte da luta do movimento, percebendo a sociedade na qual eles estão engendrados, estes conseguirão se libertar e mudar seu status quo, assim passando a ter um outro olhar em relação a sociedade, ou seja, fazendo uma releitura do mundo.

\section{REFERÊNCIAS BIBLIOGRÁFICAS}

BEZERRA NETO, L. "Sem Terra Aprende e Ensina: Um estudo sobre as práticas educativas do Movimento dos Trabalhadores Rurais Sem Terra - MST" - Campinas, autores associados, 1999.

BRASIL, "Estatuto da criança e do adolescente (ECA)”, Lei 8.069, de 13 de Julho de 1.990 .

BRASIL, “Lei de Diretrizes e Bases da Educação Nacional (LDB)”, Lei 9.394 de 20 de Dezembro de 1996. 
CALDART, R. S. “O currículo das escolas do MST”. In: Alfabetização e Cidadania, n. 11, Abr. 2001.

CALDART, R. S. "Pedagogia do Movimento Sem Terra”, ed. Expressão Popular, edição. 2004.

CALDART, R. S. "Educação em Movimento: Formação de educadoras e educadores no MST”. Petrópolis: Editora Vozes, 1997.

CALDART, R. S.; "Elementos para construção do Projeto Político e Pedagógico da Educação do Campo”; Seminário Estadual da Educação do Campo promovido pela Secretaria de Estado da Educação do Paraná de 9 a 11 de março de 2004; "Momento Atual da Educação do Campo"; Do Setor de Educação do Movimento dos Trabalhadores Rurais Sem Terra e da Articulação Nacional Por Uma Educação do Campo.

CARVALHO, H. M; “O camponês no capitalismo atual”; Texto publicado na Revista Sem Terra, Ano V no 19, abril/junho 2003, p.16-19.

FERNANDES, B. M.; “Delimitação conceitual de campesinato”, texto, 2004.

FREIRE, P. "Pedagogia da Autonomia” 33 a edição. São Paulo, Editora: Paz e Terra, 2006.

FREIRE, P. "Pedagogia do Oprimido”; 30ª edição. São Paulo, Editora: Paz e Terra, 2001.

FREIRE, P "Que fazer: Teoria e prática em Educação Popular” 6.ed. editora Vozes

FUNDEP, "Coragem de Educar: uma proposta de educação para o meio rural." Petrópolis: Vozes, 1995.

NASCIMENTO, C.G; "Educação, cidadania e políticas sociais: A luta pela educação básica do campo em Goiás”, Universidade Estadual de Goiás (UNG), 2004.

OLIVEIRA, M. A. "As bases filosóficas e epistemológicas de alguns projetos de educação do campo: Pretendido marxismo à aproximação ao ecletismo pós-moderno", 2008, Tese (Doutorado em Educação) UFPR, Paraná.

WANDERLEY, M. de N. B. "Raízes históricas do campesinato brasileiro". In: CARVALHO, H. M. "O campesinato no século XXI: possibilidades e condicionantes do desenvolvimento do campesinato no Brasil”. Petrópolis: Vozes, 2005.

\section{BIBLIOGRAFIA COMPLEMENTAR}

Caderno de Educação MST

Caderno de Educação MST n. 4 (Educação de Jovens e Adultos) 1994.

Caderno de Educação MST n. 5 (Alfabetização de Jovens e Adultos) 1995.

Caderno de Educação MST n. 6 (Como fazer a escola que queremos: O Planejamento) 1995.

Caderno de Educação n 8 Princípios da Educação no MST 1996.

Cadernos de Formação do MST.

MAKARENKO. A S “Poema Pedagógico”. São Paulo: Editora brasiliense, 1985. 
O que queremos com as escolas dos assentamentos. C.F. $182^{\mathrm{a}}$. ed 1993.

PALMEIRA, M. J. de O. (coord) Col. "Cidadania. Educação e a Construção da Cidadania do Homem do Campo”. Editora OEA UFBA EGBA, 1990.

PISTRAK, M. M, “Fundamentos da escola do trabalho”, ed. brasiliense, 1981.

SOUZA, M. A de. "A formação da Identidade Coletiva: Um estudo das lideranças de assentamentos rurais no pontal do paranapanema". Campinas: Unicamp, Faculdade de Educação, 1994.

SPEYER, A. M. "Educação e Campesinato, Uma Educação para o homem do meio Rural”. São Paulo: Edições Loyola, 1983.

\section{Documentos Eletrônicos:}

www.scielo.br/scielo.php?script=sci_arttext\&pid=S0101-

32622007000200005\&lng=pt\&nrm=iso\&tl... - 79k -

www.mst.org.br

"Elementos para construção do Projeto Político e Pedagógico da Educação do Campo"; "Momento Atual da Educação do Campo" www.uff.br/trabalhonecessario/ rcaldart\%20TN2.htm - 86k -

DECLARAÇÃO FINAL: "Por Uma Política Pública de Educação do Campo" www.forumeja.org.br/ec/files/2a\%20Conferência.pdf ; 